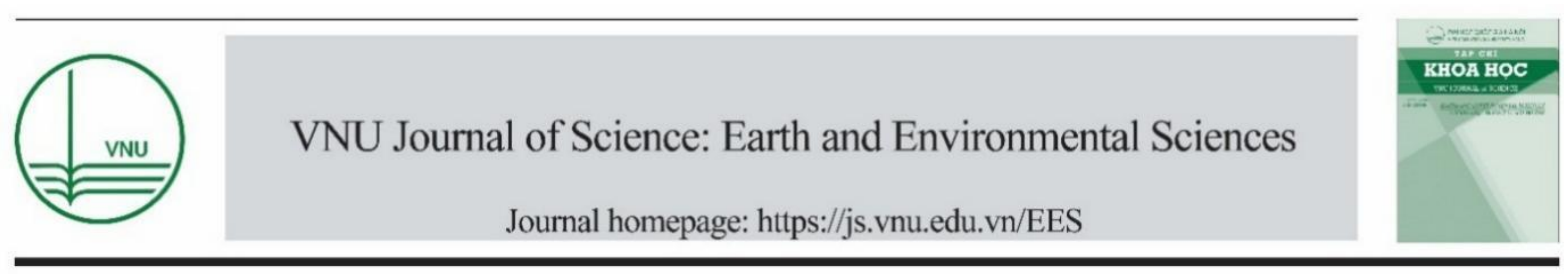

Original Article

\title{
Study on Adsorption of Nickel and Methylene Blue in Aqueous Solution by Magnetic Carboxylate-Rich Carbon
}

\author{
Doan Van Dat ${ }^{1}$, Nguyen Hoai Thuong ${ }^{1}$, Tran Thi Kieu Ngan ${ }^{2}$, Le Thi Thanh Nhi' ${ }^{2,3}$, \\ Dao My Uyen ${ }^{2,3}$, Nguyen Thi Huong ${ }^{1}$, Cong Hong Hanh ${ }^{4}$, Le Van Thuan ${ }^{2,3, *}$ \\ ${ }^{1}$ Industrial University of Ho Chi Minh City, 12 Nguyen Van Bao, Ho Chi Minh City, Vietnam \\ ${ }^{2}$ Duy Tan University, 03 Quang Trung, Da Nang city, Vietnam \\ ${ }^{3}$ Institute of Research and Development, Duy Tan University, \\ 03 Quang Trung, Da Nang city, Vietnam \\ ${ }^{4}$ Institute of Materials Science, Vietnam Academy of Science and Technology, \\ 18 Hoang Quoc Viet, Hanoi, Vietnam
}

Received 12 March 2020

Revised 24 August 2020; Accepted 29 August 2020

\begin{abstract}
In this study, magnetic carboxylate-rich carbon material $\left(\mathrm{Fe}_{3} \mathrm{O}_{4} @ \mathrm{CRC}\right)$ was synthesized via a low-temperature carbonization method and applied as an adsorbent for adsorption of Ni(II) ions and methylene blue (MB) in aqueous solution. The synthesized $\mathrm{Fe}_{3} \mathrm{O}_{4} @ \mathrm{CRC}$ was characterized by various techniques (XRD, FTIR, FE-SEM, TEM, EDX, VSM, and BET). The adsorption kinetics, isotherms, thermodynamics, and the effects of key adsorption factors, including the $\mathrm{pH}$ value, initial adsorbate concentration, contact time, adsorbent dose and temperature were investigated in detail. The results showed that $\mathrm{Fe}_{3} \mathrm{O}_{4} @ \mathrm{CRC}$ exhibited a high adsorption capacity for MB and $\mathrm{Ni}(\mathrm{II})$ with the maximum adsorption capacity of $187.26 \mathrm{mg} / \mathrm{g}$ and $106.75 \mathrm{mg} / \mathrm{g}$, respectively. The adsorption of $\mathrm{MB}$ and $\mathrm{Ni}(\mathrm{II})$ on $\mathrm{Fe}_{3} \mathrm{O}_{4} @ \mathrm{CRC}$ was a spontaneous and endothermic process, and was best described with the first-order kinetic model, Freundlich (for MB) and Langmuir (for Ni(II)) isotherm models. In addition, $\mathrm{Fe}_{3} \mathrm{O}_{4} @ \mathrm{CRC}$ could maintain a high adsorption capacity after many consecutive cycles. Therefore, the $\mathrm{Fe}_{3} \mathrm{O}_{4} @ \mathrm{CRC}$ material can be used as a highly efficient adsorbent for the removal of heavy metals and dyes from wastewater due to the advantages of high adsorption performance, easy separation, and good reusability.
\end{abstract}

Keywords: Carboxylate-rich carbon, adsorption, nickel, methylene blue, magn.

\footnotetext{
${ }^{*}$ Corresponding author.

E-mail address: levanthuan3@duytan.edu.vn
}

https://doi.org/10.25073/2588-1094/vnuees.4586 


\title{
Nghiên cứu khả năng hấp phụ niken và xanh methylen trong dung dịch nước của vật liệu cacbon từ tính giàu cacboxylat
}

\author{
Đoàn Văn Đạt ${ }^{1}$, Nguyễn Hoài Thương ${ }^{1}$, Trần Thị Kiều Ngân ${ }^{2}$, Lê Thị Thanh Nhi ${ }^{2,3}$, \\ Đào Mỹ Uyển ${ }^{2,3}$, Nguyễn Thị Hương ${ }^{1}$, Công Hồng Hạnh ${ }^{4}$, Lê Văn Thuận ${ }^{2,3, *}$ \\ ${ }^{1}$ Truò̀ng Đại học Công nghiệp Thành phố Hồ Chí Minh, \\ Số 12 Nguyễn Văn Bảo, Thành phố Hồ Chí Minh, Việt Nam \\ ${ }^{2}$ Truờng Đại học Duy Tân, 03 Quang Trung, Đà Nã̃ng, Việt Nam \\ ${ }^{3}$ Viện Nghiên cứu và Phát triển Công nghệ cao, Trương Đại học Duy Tân, \\ 03 Quang Trung, Đà Nã̃ng, Việt Nam \\ ${ }^{4}$ Viện Khoa học vật liệu, Viện Hàn lâm Khoa học và Công nghệ Việt Nam, \\ 18 Hoàng Quốc Việt, Hà Nội, Việt Nam \\ Nhận ngày 12 tháng 3 năm 2020 \\ Chỉnh sửa ngày 24 tháng 8 năm 2020; Chấp nhận đăng ngày 29 tháng 8 năm 2020
}

\begin{abstract}
Tóm tắt: Bài báo trình bày kết quả tổng hợp vật liệu cacbon từ tính giàu cacboxylat $\left(\mathrm{Fe}_{3} \mathrm{O}_{4} @ \mathrm{CRC}\right)$ và sử dụng vật liệu này để hấp phụ ion niken $(\mathrm{Ni}(\mathrm{II}))$ và xanh methylen $(\mathrm{MB})$ trong dung dịch nước. $\mathrm{Fe}_{3} \mathrm{O}_{4} @ \mathrm{CRC}$ được tổng hợp bằng phương pháp cacbon hóa ở nhiệt độ thấp hỗn hợp gồm sắt (III) clorua và natri gluconat. Các đặc trưng của vật liệu $\mathrm{Fe}_{3} \mathrm{O}_{4} @ \mathrm{CRC}$ được xác định bằng nhiều phương pháp khác nhau (XRD, FTIR, FE-SEM, TEM, EDX, VSM, BET) trước khi khảo sát khả năng hấp phụ. Ảnh hưởng của các yếu tố hấp phụ như $\mathrm{pH}$, nồng độ ban đầu, thời gian tiếp xúc, liều lượng chất hấp phụ và nhiệt độ đã được nghiên cứu chi tiết. Kết quả cho thấy $\mathrm{Fe}_{3} \mathrm{O}_{4} @ \mathrm{CRC}$ có khả năng hấp phụ cao đối với $\mathrm{MB}$ và $\mathrm{Ni}(\mathrm{II})$ với dung lượng hấp phụ cực đại lần lượt là $187.26 \mathrm{mg} / \mathrm{g}$ và 106.75 $\mathrm{mg} / \mathrm{g}$. Sự hấp phụ của $\mathrm{MB}$ và $\mathrm{Ni}(\mathrm{II})$ trên $\mathrm{Fe}_{3} \mathrm{O}_{4} @ \mathrm{CRC}$ là quá trình tự phát, thu nhiệt và được mô tả tốt nhất với mô hình động học bậc một, mô hình đẳng nhiệt Freundlich (đối với $\mathrm{MB}$ ) và Langmuir (đối với $\mathrm{Ni}(\mathrm{II})$ ). Ngoài ra, $\mathrm{Fe}_{3} \mathrm{O}_{4} @ \mathrm{CRC}$ duy trì tốt khả năng hấp phụ qua nhiều lần tái sử dụng. Với khả năng hấp phụ cao, tổng hợp dễ dàng cùng với khả năng thu hồi và tái sử dụng cao, $\mathrm{Fe}_{3} \mathrm{O}_{4} @ \mathrm{CRC}$ có thể trở thành chất hấp thụ tiềm năng để xử lý các ion kim loại nặng và phẩm màu nhuộm trong nước thải.
\end{abstract}

Từ khóa: Cacbon giàu cacboxylat, hấp phụ, niken, xanh methylen, từ tính.

\section{Mở đầu}

Sự phát triển nhanh chóng của các ngành công nghiệp như luyện kim, xi mạ, dệt may, in ấn, v.v., đã và đang làm gia tăng lượng kim loại nặng và chất nhuộm hữu cơ thải ra môi trường. Hầu hết các chất ô nhiễm này có độc tính cao, khó phân hủy sinh học, có xu hướng tích tụ lâu dài trong các cơ thể sống, gây ra các tác động tiêu cực cho hệ sinh thái và sức khỏe con người dù ở hàm lượng nhỏ [1]. Chẳng hạn như, sự tồn tại của niken (Ni) - một kim loại nặng được sử dụng rộng rãi trong sản xuất điện cực, pin điện, luyện kim, xi mạ và trong công nghiệp hợp kim - có thể

\footnotetext{
*Tác giả liên hệ.

Dịa chi email: levanthuan3@duytan.edu.vn

https://doi.org/10.25073/2588-1094/vnuees.4586
} 
gây ung thư phổi, thoái hóa xương và gây đột biến gen [2]. Một trong những phẩm màu nhuộm hữu cơ được sử dụng phổ biến nhất trong công nghiệp dệt nhuộm, thuộc da và chế biến thực phẩm là xanh methylen (methylene blue, $\mathrm{MB}$ ). Về độc tính, $\mathrm{MB}$ có thể gây ra các bệnh về mắt, da, đường hô hấp, tiêu hóa và thậm chí gây ung thư. Nồng độ của $\mathrm{MB}$ trong nước quá cao sẽ cản trở hấp phụ oxy vào trong nước, do đó làm ảnh hưởng đến sự sinh trưởng của các động thực vật thủy sinh [3]. Bên cạnh đó, nước thải từ các khu công nghiệp có thành phần phức tạp thường chứa đồng thời các hợp chất hữu cơ và vô cơ. Đặc biệt, trong nước thải từ các nhà máy dệt nhuộm và thuộc da ngoài các chất hữu cơ tạo màu còn có thể tìm thấy một lượng lớn các ion kim loại nặng như $\mathrm{Cd}(\mathrm{II}), \mathrm{Cu}(\mathrm{II}), \mathrm{Co}(\mathrm{II})$ và $\mathrm{Ni}(\mathrm{II})$ [4]. Vì vậy, nghiên cứu tách các ion kim loại nặng và phẩm màu nhuộm độc hại từ các nguồn nước bị ô nhiễm để bảo vệ sức khỏe cộng đồng là vấn đề quan trọng và đang được nhiều nhà khoa học quan tâm.

Hấp phụ là một trong những phương pháp hóa lý phổ biến để xử lý kim loại nặng và phẩm màu nhuộm trong nước thải do sự đơn giản trong thiết kế vận hành, chi phí thấp, hiệu quả cao, nguồn vật liệu hấp phụ dồi dào và đa dạng [5]. Hiệu suất xử lý của phương pháp này phần lớn phụ thuộc vào bản chất của vật liệu hấp phụ được sử dụng. Hiện nay, đã có nhiều loại chất hấp phụ khác nhau được phát triển để xử lý kim loại nặng và phẩm màu nhuộm như zeolite, silica, chitin, chitosan, hydroxyapatit, bentonit và vật liệu cacbon [6-13]. Trong số đó, vật liệu cacbon bao gồm than hoạt tính, than sinh học, ống nano cacbon, graphen được dùng nhiều nhất trong xử lý nước thải do sở hữu những tính chất đặc biệt như có độ xốp và diện tích bề mặt lớn, khối lượng nhẹ, bền trong các môi trường khác nhau, có dung lượng hấp phụ cao đối với cả kim loại và các chất hữu cơ [14].

Gần đây, một vật liệu cacbon khác cũng được sử dụng khá phổ biến trong xử lý nước thải đó là cacbon giàu nhóm chức cacboxylat (carboxylate-rich carbon, $\mathrm{CRC}$ ). Khác với vật liệu cacbon thông thường, $\mathrm{CRC}$ có nhiều nhóm chức cacboxylat (COO-) nên có thể phân tán tốt trong môi trường nước nhờ hình thành liên kết hydro với phân tử nước [15]. Bên cạnh đó, các nhóm chức cacboxylat và hydroxyl $(-\mathrm{OH})$ tồn tại trên bề mặt CRC có khả năng tạo liên kết mạnh mẽ với các cation kim loại và các hợp chất hữu cơ khác, từ đó làm tăng khả năng hấp phụ của CRC. Hơn nữa, cấu trúc xốp, diện tích bề mặt lớn của $\mathrm{CRC}$ cũng là ưu điểm nổi bật cho ứng dụng hấp phụ [16].

Thông thường đối với vật liệu hấp phụ, diện tích bề mặt càng cao khả năng hấp phụ càng lớn. Một trong những phương pháp để tăng diện tích bề mặt vật liệu hấp phụ là tăng độ xốp và giảm kích thước hạt. Chính vì vậy vật liệu ở dạng bột thường có dung lượng hâp phụ cao hơn so với dạng viên và dạng mảnh. Tuy nhiên, một thách thức lớn của việc sử dụng vật liệu hấp phụ dạng bột là khó thu hồi sau khi sử dụng, khi đó vật liệu hấp phụ có thể trở thành chất ô nhiễm thứ cấp [17]. Trong khi đó các phương pháp truyền thống dùng để tách vật liệu hấp phụ sau khi sử dụng như ly tâm, sa lắng hoặc lọc tốn nhiều thời gian và chi phí cao. Một trong những phương pháp triển vọng để giải quyết vấn đề này là áp dụng kỹ thuật tách bằng từ tính. Tức là tích hợp vào vật liệu hấp phụ một lượng chất có khả năng phản ứng với từ trường như $\mathrm{Fe}_{3} \mathrm{O}_{4}, \mathrm{Fe}_{2} \mathrm{O}_{3}, \mathrm{NiFe}_{2} \mathrm{O}_{4}$, $\mathrm{CoFe}_{2} \mathrm{O}_{4}, \mathrm{CuFe}_{2} \mathrm{O}_{4}, \mathrm{ZnFe}_{2} \mathrm{O}_{4}$, sau khi hấp phụ vật liệu chứa từ tính sẽ dễ dàng thu hồi bằng từ trường và sau đó có thể tái sử dụng nhiều lần. Như vậy có thể giúp giảm đáng kể chi phí xử lý. Trong số vật liệu có từ tính nêu trên, oxit sắt từ $\mathrm{Fe}_{3} \mathrm{O}_{4}$ được sử dụng rộng rãi nhất do có tính tương thích sinh học cao, độc tính thấp, từ tính mạnh và dễ tổng hợp [18]. Bên cạnh đó, bản thân $\mathrm{Fe}_{3} \mathrm{O}_{4}$ cũng có khả năng hấp phụ đối với kim loại nặng và phẩm màu nhuộm, đặc biệt ở kích thước nano $[19,20]$. Do đó, sử dụng nano sắt từ $\mathrm{Fe}_{3} \mathrm{O}_{4}$ để kết hợp với vật liệu hấp phụ từ tính sẽ mang lại hiệu quả kép là vừa tăng khả năng hấp phụ và giúp cho việc thu hồi tái sử dụng nhanh chóng và dễ dàng hơn.

Trong nghiên cứu này, chúng tôi tổng hợp vật liệu cacbon từ tính giàu cacboxylat $\left(\mathrm{Fe}_{3} \mathrm{O}_{4} @ \mathrm{CRC}\right)$ ứng dụng để hấp phụ kim loại nặng và phẩm màu nhuộm trong dung dịch nước. Vật liệu $\mathrm{Fe}_{3} \mathrm{O}_{4} @$ @RC được tổng hợp bằng 
phương pháp cacbon hóa hỗn hợp gồm sắt (III) clorua và natri gluconat ở nhiệt độ thấp. Trong đó, natri gluconat đóng vai trò là nguồn cacbon để tạo $\mathrm{CRC}$, và nano $\mathrm{Fe}_{3} \mathrm{O}_{4}$ được hình thành đồng thời với $\mathrm{CRC}$ thông qua quá trình nhiệt phân phức sắt (III) carboxylat. Nhờ quá trình cacbon hóa được thực hiện ở nhiệt độ thấp $\left(300^{\circ} \mathrm{C}\right)$, một lượng lớn nhóm hydroxyl và carboxylat của natri gluconat có thể được giữ lại trong CRC. Các nhóm chức này, như đã đề cập ở trên, đóng một vai trò quan trọng trong việc cố định và phân bố đồng nhất của các hạt nano $\mathrm{Fe}_{3} \mathrm{O}_{4}$ cũng như tăng cường khả năng hấp phụ của vật liệu. Các đặc trưng của $\mathrm{Fe}_{3} \mathrm{O}_{4} @ \mathrm{CRC}$ được xác định bằng các phương pháp hóa-lý hiện đại và khả năng hấp phụ của vật liệu đối với kim loại nặng và phẩm màu nhuộm được khảo sát. Trong nghiên cứu này, chúng tôi chọn $\mathrm{Ni}(\mathrm{II})$ và $\mathrm{MB}$ như kim loại nặng và phẩm màu nhuộm điển hình thường tìm thấy nhiều trong nước thải công nghiệp làm đối tượng để khảo sát khả năng hấp phụ của vật liệu.

\section{Vật liệu và phương pháp}

\subsection{Hóa chất}

Tất cả các hóa chất chính được sử dụng trong nghiên cứu này bao gồm natri gluconat $\left(\mathrm{C}_{6} \mathrm{H}_{11} \mathrm{NaO}_{7}, 98 \%\right)$, sắt (III) clorua khan $\left(\mathrm{FeCl}_{3}\right.$, $\geq 99,99 \%$ ), niken (II) sunfat hexahydrat $\left(\mathrm{NiSO}_{4} \cdot 6 \mathrm{H}_{2} \mathrm{O}\right)$, natri hydroxit $(\mathrm{NaOH}, \geq 98,5 \%)$, axit hydrochloric $(\mathrm{HCl}, 37 \%)$, xanh methylen $\left(\mathrm{C}_{16} \mathrm{H}_{18} \mathrm{ClN}_{3} \mathrm{~S}, \quad \geq 95 \%\right)$, ethanol $\left(\mathrm{C}_{2} \mathrm{H}_{5} \mathrm{OH}\right.$, $\geq 99,8 \%$ ) được mua từ hãng Sigma-Aldrich (Singapore).

\subsection{Tổnghơp $\mathrm{Fe}_{3} \mathrm{O}_{4} @ \mathrm{CRC}$}

Quy trình tổng hợp $\mathrm{Fe}_{3} \mathrm{O}_{4} @ \mathrm{CRC}$ được mô tả ở Hình 1. Cụ thể, hòa tan $3 \mathrm{~g} \mathrm{NaC} \mathrm{N}_{6} \mathrm{H}_{11} \mathrm{O}_{7}$ trong $20 \mathrm{~mL}$ nước cất, sau đó thêm $1 \mathrm{~g} \mathrm{FeCl}_{3}$ và khuấy đều trong 30 phút ở nhiệt độ phòng. Chuyển hỗn hợp thu được vào đĩa petri và cho bay hơi ở $80^{\circ} \mathrm{C}$ cho đến khi tạo thành dạng gel. Tiếp theo, cho gel vào cốc nung đậy kín nắp và nung ở nhiệt độ $300{ }^{\circ} \mathrm{C}$ trong 2 giờ. Sản phẩm sau khi nung được rửa sạch nhiều lần bằng nước cất, sau đó bằng $\mathrm{C}_{2} \mathrm{H}_{5} \mathrm{OH}$ và sấy khô ở nhiệt độ $105^{\circ} \mathrm{C}$ trong 6 giờ. Sản phẩm thu được có dạng hình khối xốp được nghiền nhỏ và sàng qua rây kích thước $145 \mu \mathrm{m}$.

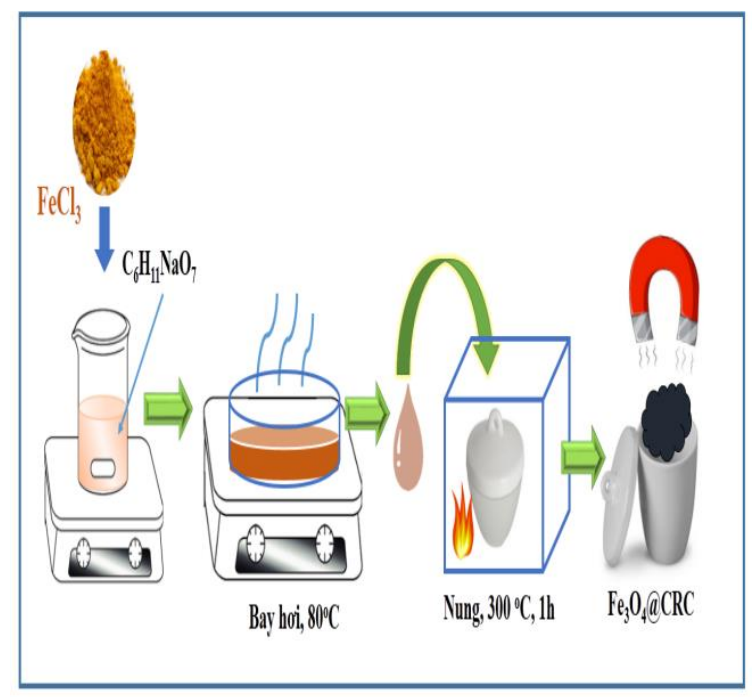

Hình 1. Hình minh họa quá trình tổng hợp $\mathrm{Fe}_{3} \mathrm{O}_{4} @ \mathrm{CRC}$.

\subsection{Khảo sát khả năng hấp phu của vật liệu}

Khả năng hấp phụ $\mathrm{Ni}(\mathrm{II})$ và $\mathrm{MB}$ của vật liệu $\mathrm{Fe}_{3} \mathrm{O}_{4} @ \mathrm{CRC}$ được khảo sát ở những thông số hấp phụ như nhiệt độ, $\mathrm{pH}$, liều lượng chất hấp phụ, nồng độ chất bị hấp phụ và thời gian khác nhau. Dung dịch chuẩn của $\mathrm{Ni}(\mathrm{II})$ và $\mathrm{MB}$ có nồng độ $1000 \mathrm{mg} / \mathrm{L}$ được chuẩn bị từ các hóa chất tinh khiết dùng cho phân tích. Các dung dịch có nồng độ khác nhau dùng để nghiên cứu hấp phụ được pha từ dung dịch chuẩn trên. Đối với mỗi thí nghiệm, một lượng xác định vật liệu hấp phụ $(0,05 \mathrm{~g})$ được cho vào cốc bình nón $150 \mathrm{~mL}$ có chứa $50 \mathrm{~mL}$ dung dịch $\mathrm{Ni}$ (II) hoặc $\mathrm{MB}$ có nồng độ, $\mathrm{pH}$, nhiệt độ xác định và được khuấy đều trên máy rung lắc. Sau khi hấp phụ, vật liệu hấp phụ được thu hồi bằng nam châm vĩnh cữu. Hàm lượng chất bị hấp phụ còn lại sau khi hấp phụ được xác định bằng phương pháp phổ hấp phụ nguyên tử AAS (đối với $\mathrm{Ni}(\mathrm{II})$ ) trên máy quang phổ iCE 3500 (Thermo Scientific, Đức) và phương pháp quang trắc đối với $\mathrm{MB}$ trên máy UV - VIS Cary 60 (Mỹ) tại bước sóng $665 \mathrm{~nm}$. Các giá trị pH khác nhau của dung dịch được 
điều chỉnh bằng cách thêm từ từ dung dịch $\mathrm{HCl}$ 0 ., $\mathrm{M}$ hoặc $\mathrm{NaOH} 0,1 \mathrm{M}$ với sự trợ giúp của máy đo pH InoLab Multi 9310 IDS (Đức). Sự ảnh hưởng của các thông số hấp phụ đến hiệu suất hấp phụ được nghiên cứu bằng cách thay đổi một thông số cần khảo sát và giữ cố định các thông số còn lại ở điều kiện tối ưu (thông tin chi tiết về điều kiện tiến hành thí nghiệm được thể hiện ở từng hình tương ứng trong phần kết quả và thảo luận). Tất cả các thí nghiệm được thực hiện ít nhất ba lần và lấy kết quả trung bình.

Hiệu suất hấp phụ $(R, \%)$, dung lượng hấp phụ tại thời điểm $t\left(q_{t}, \mathrm{mg} / \mathrm{g}\right)$ và tại thời điểm cân bằng $\left(q_{e}, \mathrm{mg} / \mathrm{g}\right)$ được tính theo các công thức sau:

$$
\begin{gathered}
R=\frac{C_{0}-C_{e}}{C_{0}} \times 100 \\
q_{t}=\frac{C_{0}-C_{t}}{m} \times V
\end{gathered}
$$

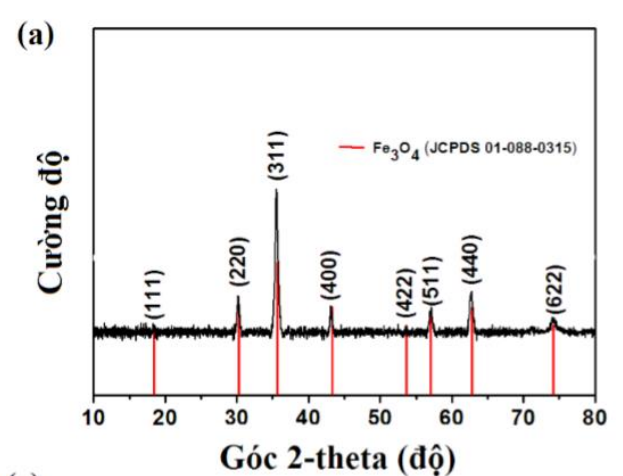

(c)

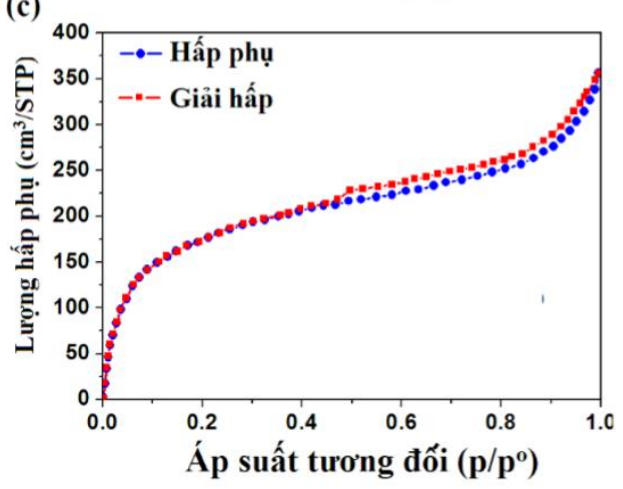

$$
q_{e}=\frac{C_{0}-C_{e}}{m} \times V
$$

Trong đó, $C_{o}, C_{t}$, và $C_{e}(\mathrm{mg} / \mathrm{L})$ lần lượt là nồng độ $\mathrm{Ni}$ (II) hoặc $\mathrm{MB}$ ban đầu tại thời điểm $t$ và tại cân bằng; $V(\mathrm{~L})$ là thể tích dung dịch chất bị hấp phụ; $m(\mathrm{~g})$ là khối lượng chất hấp phụ.

\subsection{Khảo sát khả năng tái sủ dụng của vật liệu}

Để đánh giá khả năng tái sử dụng của vật liệu, sau khi hấp phụ với dung dịch ion $\mathrm{Ni}(\mathrm{II})$ hoặc MB ở điều kiện tối ưu, vật liệu được thu hồi bằng nam châm được ngâm trong $50 \mathrm{~mL}$ dung dịch $\mathrm{HCl}$ 0,1M. Sau đó, vật liệu được thu hồi, sấy khô và tiến hành hấp phụ ở các vòng tiếp theo. Quá trình hấp phụ-giải hâp phụ được lặp lại 5 lần. Bên cạnh đó, khả năng thu hồi cũng được đánh giá qua việc so sánh khối lượng của vật liệu ban đầu và sau khi sử dụng.
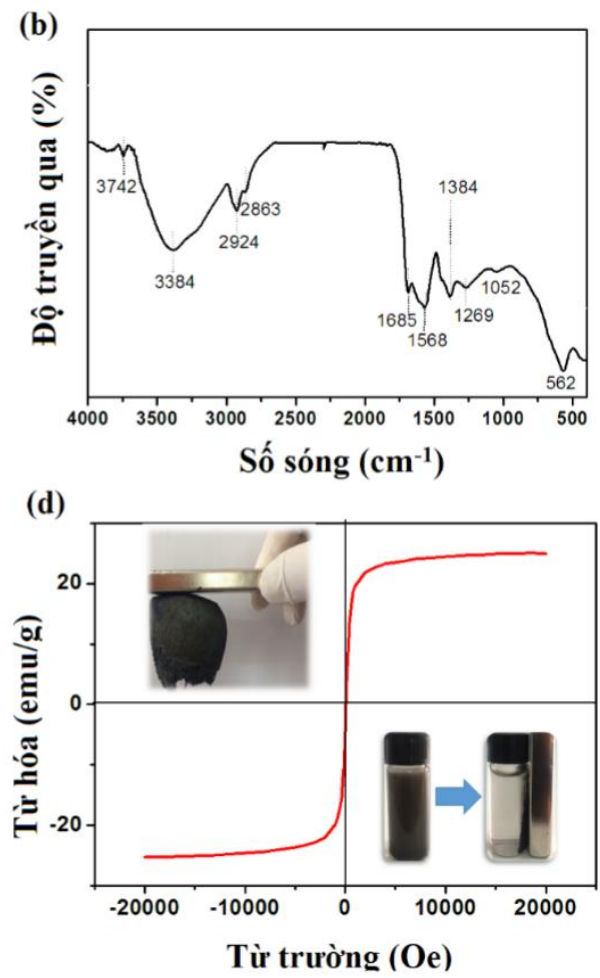

Hình 2. Phổ XRD (a), phổ FITR (b), đường đẳng nhiệt hấp phụ - khử hấp phụ $\mathrm{N}_{2}$ (c) và đường cong từ hóa của mẫu $\mathrm{Fe}_{3} \mathrm{O}_{4} @ \mathrm{CRC}$. 


\section{Kết quả và thảo luận}

\subsection{Các đặc trung của vật liệu}

Cấu trúc và thành phần tinh thể của $\mathrm{Fe}_{3} \mathrm{O}_{4} @ \mathrm{CRC}$ được khảo sắt bằng phổ XRD. Từ Hình $2 \mathrm{a}$ cho thấy trong giản đồ XRD của vật liệu $\mathrm{Fe}_{3} \mathrm{O}_{4} @$ CRC xuất hiện các đỉnh nhiễu xạ tại góc $2 \theta=18,46^{\circ}, \quad 30,09^{\circ}, 35,49^{\circ}, 43,27^{\circ}, \quad 53,60^{\circ}$, $57,07^{\circ}, 62,69^{\circ}$ và $74,16^{\circ}$ đặc trưng cho tinh thể lập phương của $\mathrm{Fe}_{3} \mathrm{O}_{4}$ (JCPDS No 01-088-0315). Không phát hiện các đỉnh đặc trưng cho hematit, sắt hydroxit, và các tạp chất khác, cho thấy $\mathrm{Fe}_{3} \mathrm{O}_{4}$ được tổng hợp trong vật liệu $\mathrm{Fe}_{3} \mathrm{O}_{4} @ \mathrm{CRC}$ có độ tinh khiết cao. Ngoài ra, trong phổ XRD của $\mathrm{Fe}_{3} \mathrm{O}_{4} @$ CRC cũng không quan sát thấy đỉnh nhiê̂u xạ rõ ràng đặc trưng cho cacbon, chứng tỏ
CRC là cacbon vô định hình [21]. Phổ hồng ngoại FITR (Hình $2 b$ ) được sử dụng để xác định các nhóm chức bề mặt của vật liệu $\mathrm{Fe}_{3} \mathrm{O}_{4} @ \mathrm{CRC}$. Trong phổ FTIR có thể dễ dàng phát hiện dải hấp thụ đặc trưng cho liên kết $\mathrm{Fe}-\mathrm{O}$ của hạt nano $\mathrm{Fe}_{3} \mathrm{O}_{4}$ ở bước sóng $562 \mathrm{~cm}^{-1}$ [5]. Các đỉnh hấp thụ đặc trưng cho các dao động kéo dài của $\mathrm{H}-\mathrm{C}$ $\mathrm{H}$ được quan sát ở các bước sóng $2924 \mathrm{~cm}^{-1}$ và $2863 \mathrm{~cm}^{-1}$. Sự xuất hiện của các dải ở $1052 \mathrm{~cm}^{-1}$ và $1568 \mathrm{~cm}^{-1}$ tương ứng với dao động của liên kết $\mathrm{C}-\mathrm{O}$ và $\mathrm{C}-\mathrm{C}-\mathrm{C}$ trong vòng thơm. Sự hiện diện của các nhóm hydroxyl $(\mathrm{O}-\mathrm{H})$ trong vật liệu tổng hợp $\mathrm{Fe}_{3} \mathrm{O}_{4} @$ @RC được chứng minh bằng hai dải nằm ở $3742 \mathrm{~cm}^{-1}$ và $3384 \mathrm{~cm}^{-1}$ [22]. Các đỉnh hấp thụ ở $1685 \mathrm{~cm}^{-1}$ và $1269 \mathrm{~cm}^{-1}$ đặc trưng cho dao động kéo dài của $\mathrm{C}=\mathrm{O}$ trong nhóm cacboxylat của CRC.
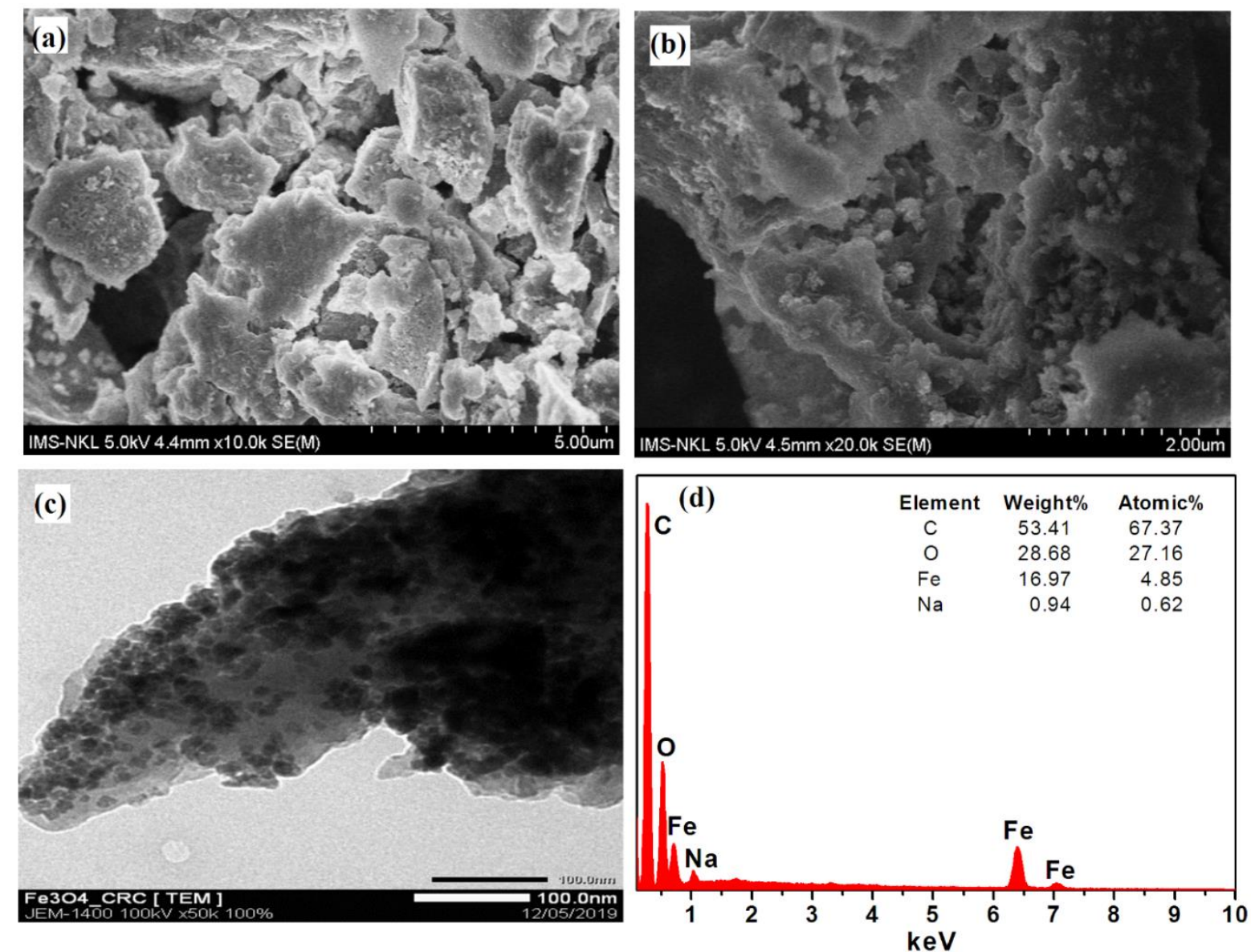

Hình 3. Ảnh FE-SEM (a, b), ảnh TEM (c) và phổ EDX (d) của mẫu $\mathrm{Fe}_{3} \mathrm{O}_{4} @ \mathrm{CRC}$. 
Hình $2 \mathrm{c}$ thể hiện đường đẳng nhiệt hấp phụ khử hấp phụ $\mathrm{N}_{2}$ trên $\mathrm{Fe}_{3} \mathrm{O}_{4} @$ CRC. Đường đẳng nhiệt có dạng hỗn hợp của dạng I và dạng IV theo phân loại của IUPAC, điều này chứng tỏ sự tồn tại đồng thời các cấu trúc xốp vi lỗ (micropore) và lỗ trung bình (mesopore). Diện tích bề mặt riêng và thể tích lỗ trống của $\mathrm{Fe}_{3} \mathrm{O}_{4} @ \mathrm{CRC}$ được tính theo phương BET có giá trị tương ứng là $308,7 \mathrm{~m}^{2} / \mathrm{g}$ và $0,398 \mathrm{~cm}^{3} / \mathrm{g}$. Cùng với tính chất kết cấu bề mặt, độ từ hóa là một đại lượng rất quan trọng đối với vật liệu hấp phụ từ tính bởi nó ảnh hưởng đến khả năng thu hồi vật liệu sau khi hấp phụ bằng từ trường. Tính chất từ và từ hóa bão hòa của vật liệu có thể được xác định thông qua đường cong từ hóa. Đường cong từ hóa của $\mathrm{Fe}_{3} \mathrm{O}_{4} @ \mathrm{CRC}$ ở $300 \mathrm{~K}$ được thể hiện trong Hình $2 \mathrm{~d}$. Từ Hình $2 \mathrm{~d}$ có thể thấy đường cong từ
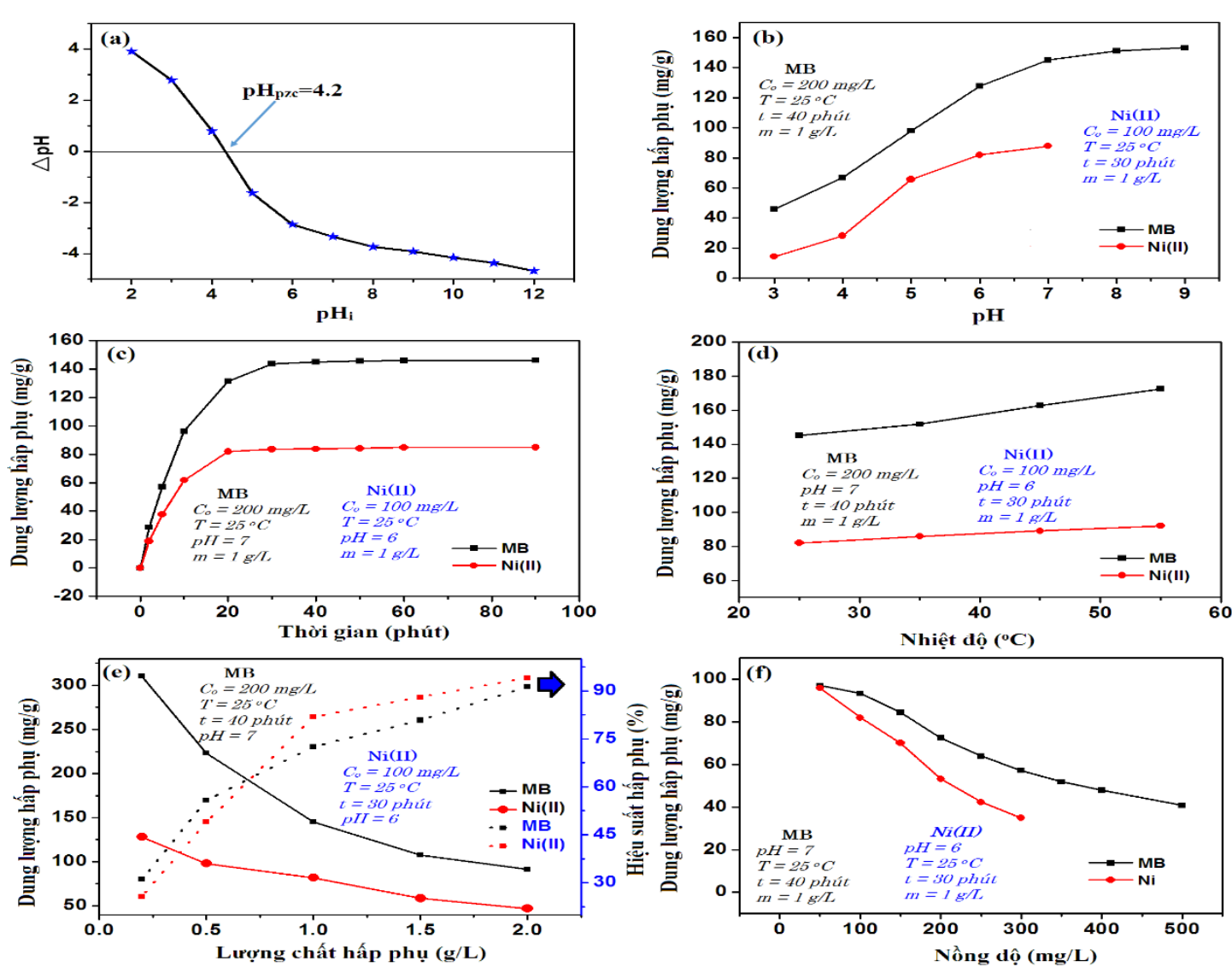

Hình 4. Điểm đẳng điện của $\mathrm{Fe}_{3} \mathrm{O}_{4} @ \mathrm{CRC}(\mathrm{a})$, ảnh hưởng của $\mathrm{pH}(\mathrm{b})$, thời gian $(\mathrm{c})$, nhiệt độ $(\mathrm{d})$, lượng chấp hấp phụ (e) và nồng độ ban đầu (f) đến khả năng hấp phụ $\mathrm{MB}$ và $\mathrm{Ni}(\mathrm{II})$ của $\mathrm{Fe}_{3} \mathrm{O}_{4} @ \mathrm{CRC}$.
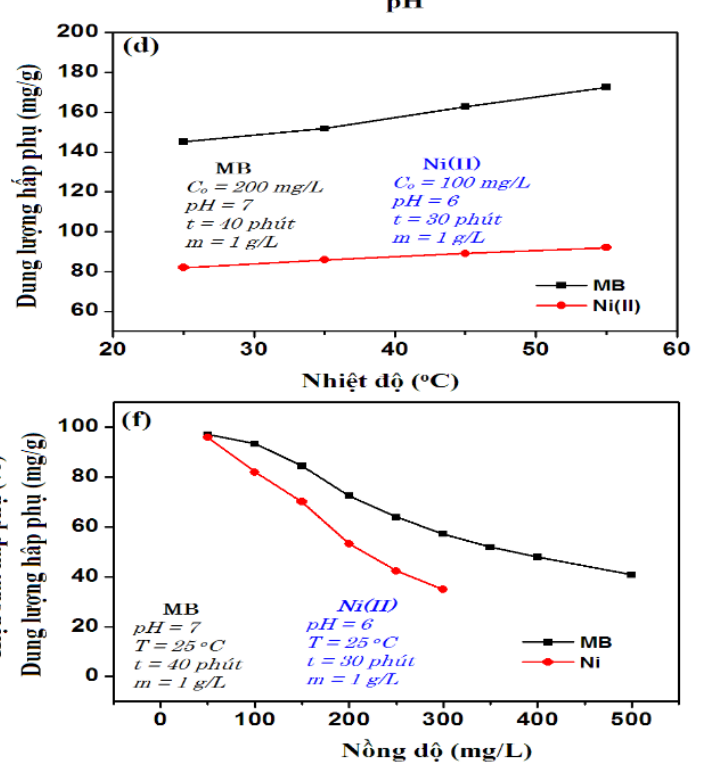

hóa của vật liệu $\mathrm{Fe}_{3} \mathrm{O}_{4} @ \mathrm{CRC}$ có dạng chữ "S" đặc trưng cho vật liệu có tính chất siêu thuận từ. Giá trị từ hóa bão hòa của $\mathrm{Fe}_{3} \mathrm{O}_{4} @ \mathrm{CRC}$ được xác định có giá trị là 30,02 emu/g. Mặc dù giá trị từ hóa bão hòa của $\mathrm{Fe}_{3} \mathrm{O}_{4} @ \mathrm{CRC}$ không quá cao so với $\mathrm{Fe}_{3} \mathrm{O}_{4}(\sim 60 \mathrm{emu} / \mathrm{g})$, nhưng chúng vẫn sở hữu khả năng phản hồi tốt với từ trường. Như có thể thấy trong hình được chèn trong Hình $2 \mathrm{~d}$, khối $\mathrm{Fe}_{3} \mathrm{O}_{4} @$ @ CRC có thể được giữ chặt vào thanh nam châm và các hạt $\mathrm{Fe}_{3} \mathrm{O}_{4} @ \mathrm{CRC}$ nhanh chóng được kéo sát vào thành lọ khi được áp từ trường của thanh nam châm. Điều này chứng tỏ $\mathrm{Fe}_{3} \mathrm{O}_{4} @ \mathrm{CRC}$ có thể được thu hồi hiệu quả bằng công nghệ tách từ tính. Hình thái và thành phần hóa học bề mặt của $\mathrm{Fe}_{3} \mathrm{O}_{4} @ \mathrm{CRC}$ được khảo sát bằng phương pháp FE-SEM, TEM và $\mathrm{EDX}$. Kết quả khảo sát được trình bày ở Hình 3 . 


\subsection{Các yếu tố ảnh hưởng đến khả năng hấp phu của $\mathrm{Fe}_{3} \mathrm{O}_{4} @ \mathrm{CRC}$}

Điện tích bề mặt là một thông số quan trọng ảnh hưởng đến khả năng hấp phụ của vật liệu thông qua lực hút tĩnh điện. Thông số này phụ thuộc vào bản chất của từng vật liệu và giá trị $\mathrm{pH}$ của dung dịch chất bị hấp phụ. Khả năng tương tác tĩnh điện của vật liệu đối với chất bị hấp phụ được đánh giá thông qua điểm đẳng điện $\mathrm{pH}_{\mathrm{pzc}}$ (là giá trị $\mathrm{pH}$ của dung dịch mà tại đó bề mặt vật liệu trung hòa về điện tích). Khi $\mathrm{pH}$ của dung dịch nhỏ hơn $\mathrm{pH}_{\mathrm{pzc}}$ thì bề mặt vật liệu tích điện dương, thuận lợi cho hấp phụ các anion; ngược lại $\mathrm{pH}$ dung dịch lớn hơn $\mathrm{pH}_{\mathrm{pzc}}$ bề mặt sẽ tích điện âm và thuận lợi cho hấp phụ đối với các cation. Kết quả của điểm đẳng điện được thể hiện ở Hình 4a.

Từ Hình 4a cho thấy $\mathrm{pH}_{\mathrm{pzc}}$ của $\mathrm{Fe}_{3} \mathrm{O}_{4} @ \mathrm{CRC}$ là 4,2, tức là $\mathrm{Fe}_{3} \mathrm{O}_{4} @$ CRC sẽ tích điện dương hoặc âm khi $\mathrm{pH}$ của dung dịch chất hấp phụ tương ứng nhỏ hơn hoặc lớn hơn 4,2 . Như vậy, nếu $\mathrm{pH}$ của dung dịch lớn hơn 4,2 sẽ thuận lợi cho hấp phụ ion kim loại nặng và phẩm màu nhuộm cation như MB. Thật vậy, như được trình bày ở Hình $4 \mathrm{~b}$, ở $^{\mathrm{pH}}<4,2$ dung lượng hấp phụ của $\mathrm{Fe}_{3} \mathrm{O}_{4} @$ CRC đối với $\mathrm{Ni}$ (II) và $\mathrm{MB}$ dều thấp, và gia tăng đáng kể khi $\mathrm{pH}>4,2$. Một nguyên nhân khác có thể giải thích cho sự hấp phụ kém của vật liệu ở $\mathrm{pH}$ thấp đó là nồng độ $\mathrm{H}^{+}$cao (ở pH thấp) sẽ cạnh tranh các tâm hấp phụ của $\mathrm{Fe}_{3} \mathrm{O}_{4} @$ CRC với các ion $\mathrm{Ni}(\mathrm{II})$ và $\mathrm{MB}$ dần đến dung lượng hấp phụ giảm, ở pH cao hơn sự cạnh tranh này sẽ giảm dần tạo điều kiện thuận lợi cho hấp phụ. Dung lượng hấp phụ $\mathrm{MB}$ ở $\mathrm{pH} 8$ và 9 không tăng nhiều so với ở $\mathrm{pH} 7$, do đó chúng tôi chọn $\mathrm{pH} 7$ cho các thí nghiệm hấp phụ MB tiếp theo. Đối với $\mathrm{Ni}(\mathrm{II})$, ở $\mathrm{pH}>7$ đã bắt đầu quan sát thấy hiện tượng kết của của ion Ni(II) dưới dạng hydroxyt. Do đó, trong nghiên cứu này chúng tôi chọn pH 6 cho các nghiên cứu tiếp theo để loại bỏ sự ảnh hưởng của quá trình kết tủa ion Ni(II).

Sự ảnh hưởng của thời gian tiếp xúc đến khả năng hấp phụ $\mathrm{MB}$ và $\mathrm{Ni}$ (II) của $\mathrm{Fe}_{3} \mathrm{O}_{4} @ \mathrm{CRC}$ được thể hiện ở Hình $4 \mathrm{c}$. Có thể thấy rằng dung lượng hấp phụ của $\mathrm{Fe}_{3} \mathrm{O}_{4} @ \mathrm{CRC}$ tăng nhanh trong 20 phút đầu, tăng chậm trong 10 phút tiếp theo và hầu như không thay đổi sau 40 phút, khi mà quá trình hấp phụ đạt cân bằng. Đối với $\mathrm{Ni}(\mathrm{II})$, quá trình hấp phụ đạt cân bằng khoảng 20-30 phút tiếp xúc, sớm hơn so với MB (đạt cân bằng sau 40 phút). Điều này có thể là do các ion $\mathrm{Ni}(\mathrm{II})$ có kích thước nhỏ hơn MB nên dễ dạng tiếp cận tâm hấp phụ hơn. Tốc độ hấp phụ tăng nhanh ở những phút đầu tiên và chậm dần khi tăng thời gian tiếp xúc là do số lượng tâm hấp phụ tự do trên bề mặt $\mathrm{Fe}_{3} \mathrm{O}_{4} @$ @RC giảm dần theo thời gian hấp phụ bởi sự chiếm các tâm hấp phụ bởi các ion $\mathrm{Ni}$ (II) hoặc MB. Hiện tượng này cũng được quan sát ở nhiều nghiên cứu hấp phụ $[23,24]$. Thời gian tiếp xúc tối ưu đối với $\mathrm{MB}$ và $\mathrm{Ni}$ (II) được chọn tương ứng ở 40 phút và 30 phút.

Ânh hưởng của nhiệt độ đến khả năng hấp phụ của $\mathrm{Fe}_{3} \mathrm{O}_{4} @$ @RC được nghiên cứu trong khoảng $25-55{ }^{\circ} \mathrm{C}$. Kết quả ở Hình $4 \mathrm{~d}$ chứng tỏ dung lượng hấp phụ phụ thuộc vào nhiệt độ rất rõ rệt. Khi tăng nhiệt độ từ $25^{\circ} \mathrm{C}$ dến $55^{\circ} \mathrm{C}$, dung lượng hấp phụ của vật liệu tăng từ 145,09 mg/g đến $172,51 \mathrm{mg} / \mathrm{g}$ đối $\mathrm{MB}$ và tăng từ $81,94 \mathrm{mg} / \mathrm{g}$ đến $92,09 \mathrm{mg} / \mathrm{g}$ đối với $\mathrm{Ni}(\mathrm{II})$. Như vậy, quá trình hấp phụ diễn ra thuận lợi ở nhiệt độ cao. Điều này có thể là do ở nhiệt độ cao, các phân tử $M B$ và $\mathrm{Ni}(\mathrm{II})$ trở nên linh động hơn và khi đó gia tăng xác suất va chạm với tâm hấp phụ làm gia tăng khả năng hấp phụ [25]. Sự gia tăng khả năng hấp phụ khi tăng nhiệt độ có thể chứng tỏ rằng hấp phụ hóa học chiếm ưu thế trong quá trình hấp phụ của $\mathrm{Ni}$ (II) và $\mathrm{MB}$ trên $\mathrm{Fe}_{3} \mathrm{O}_{4} @ \mathrm{CRC}$ [26].

Xác định liều lượng chất hấp phụ tối ưu là cần thiết cho bất kỳ quá trình hấp phụ để tăng hiệu quả loại bỏ chất ô nhiễm với một lượng chất hấp phụ vừa đủ, từ đó giảm chi phí xử lý. Ảnh hưởng của liều lượng hấp phụ được khảo sát với lượng chất hấp phụ $\mathrm{Fe}_{3} \mathrm{O}_{4} @ \mathrm{CRC}$ thay đổi trong khoảng $0,2-2 \mathrm{~g} / \mathrm{L}$ và kết quả được trình bày ở Hình $4 \mathrm{e}$. Như đã thấy trong Hình $4 \mathrm{e}$, khi tăng nồng độ chất hấp phụ, dung lượng hấp phụ của vật liệu đối với cả $\mathrm{Ni}(\mathrm{II})$ và $\mathrm{MB}$ đều giảm, trong khi hiệu suất loại bỏ tăng với tốc độ cao ở giai đoạn đầu $(0,2-1 \mathrm{~g} / \mathrm{L})$ và sau đó tăng với tốc độ nhỏ hơn khi tăng lượng chất hấp phụ từ $1 \mathrm{~g} / \mathrm{L}$ đến $2 \mathrm{~g} / \mathrm{L}$. Xu hướng giảm dung lượng hấp phụ của $\mathrm{Fe}_{3} \mathrm{O}_{4} @ \mathrm{CRC}$ có thể là do khi tăng lượng chất hấp phụ mà giữ nguyên nồng độ của các ion $\mathrm{Ni}(\mathrm{II})$ hoặc $\mathrm{MB}$, một số tâm hấp phụ trở nên dư thừa, 
bi kết tụ hoặc bi che chắn bởi các hat vật liệu dư thừa trong dung dịch, khi đó sự hấp phụ diễn ra không hiệu quả [27]. Căn cứ vào sự phụ thuộc của hiệu suất hấp phụ và dung lượng hấp phụ vào liều lượng chất hấp phụ, chúng tôi chọn liều lượng chất hấp phụ $1 \mathrm{~g} / \mathrm{L}$ là liều lượng hấp hiệu quả.

Sự ảnh hưởng của nồng độ ban đầu được khảo sát trong khoảng nồng độ từ $50 \mathrm{mg} / \mathrm{L}$ đến $500 \mathrm{mg} / \mathrm{L}$ đối với $\mathrm{MB}$ và từ $50 \mathrm{mg} / \mathrm{L}$ đến 300 $\mathrm{mg} / \mathrm{L}$ đối với $\mathrm{Ni}(\mathrm{II})$, các thông số còn lại được giữ ở điều kiện tối ưu. Kết quả ở Hình $4 \mathrm{f}$ cho thấy khi tăng nồng độ ion $\mathrm{Ni}$ (II) ban đầu từ 50 đến $150 \mathrm{mg} / \mathrm{L}$, dung lượng hấp phụ tăng dần và đạt giá trị bão hòa là $105,06 \mathrm{mg} / \mathrm{g}$. Khi tiếp tục tăng nồng độ $\mathrm{Ni}$ (II) dung lượng hấp phụ hầu như không tăng nữa do tâm hấp phụ đã bão hòa. Đối với $\mathrm{MB}$, dung lượng hấp phụ cũng tăng nhanh ở khoảng nồng độ từ $50 \mathrm{mg} / \mathrm{L}$ đến $150 \mathrm{mg} / \mathrm{L}$ do độ linh động của các phân tử $\mathrm{Ni}(\mathrm{II})$ và $\mathrm{MB}$ cao, và tâm hấp phụ của $\mathrm{Fe}_{3} \mathrm{O}_{4} @ \mathrm{CRC}$ còn dư thừa nhiều [28]. Khi tiếp tục tăng nồng độ ban đầu của $\mathrm{MB}$ đến $500 \mathrm{mg} / \mathrm{L}$ dung lượng hấp phụ của vật liệu tăng dần, điều này có thể liên quan đến sự hấp phụ đa lớp của $\mathrm{MB}$ trên $\mathrm{Fe}_{3} \mathrm{O}_{4} @ \mathrm{CRC}$. Hiệu suất hấp phụ $\mathrm{MB}$ và $\mathrm{Ni}(\mathrm{II})$ của vật liệu giảm dần khi tăng nồng độ ban đầu.

\subsection{Mô hình đẳng nhiệt và động học hấp phu}

Việc tìm ra mô hình mô tả quá trình hấp phụ của một vật liệu rất quan trọng để có thể thiết kế các điều kiện phù hợp khi áp dụng vật liệu trong thực tế. Trong nghiên cứu này, các mô hình động học bậc một (4), bậc hai (5), mô hình đẳng nhiệt
Langmuir (6) và Freundlich (7) được sử dụng để khảo sát dữ liệu hấp phụ của $\mathrm{MB}$ và $\mathrm{Ni}(\mathrm{II})$ trên $\mathrm{Fe}_{3} \mathrm{O}_{4} @ \mathrm{CRC}$. Các mô hình được mô tả bởi các phương trình toán học dưới đây [29]:

$$
\begin{aligned}
& q_{t}=q_{e}\left(1-e^{-k_{1} t}\right) \\
& q_{t}=\frac{k_{2} q_{e}^{2} t}{1+k_{2} q_{e} t} \\
& q_{e}=\frac{q_{m} K_{L} C_{e}}{1+K_{L} C_{e}} \\
& q_{e}=K_{F} C_{e}^{1 / n}
\end{aligned}
$$

Trong đó: $q_{t}(\mathrm{mg} / \mathrm{g})$ và $\mathrm{q}_{\mathrm{e}}(\mathrm{mg} / \mathrm{g})$ lần lượt là lượng Ni(II) hoặc MB hấp phụ trên vật liệu tại thời điểm $t$ (phút) và thời điểm cân bằng; $k_{1}$ $\left(1 /\right.$ phút) và $\mathrm{k}_{2}(\mathrm{~g} / \mathrm{mg} / \mathrm{phút})$ tương ứng là hằng số tốc độ bậc một và hai; $K_{L}(\mathrm{~L} / \mathrm{mg})$ và $K_{F}$ $\left[(\mathrm{mg} / \mathrm{g}) .(\mathrm{L} / \mathrm{mg})^{1 / \mathrm{n}}\right]$ lần lượt là hằng số Langmuir và Freundlich; $q_{m}(\mathrm{mg} / \mathrm{g})$ dung lượng hấp phụ cực đại; $1 / n$ là hằng số dị thể chỉ ra cường độ hấp phụ của vật liệu.

Sự phù hợp của các mô hình với các điểm thực nghiệm và các thông số hấp phụ được tính toán sử dụng chức năng Fitting của chương trình Origin 8,5 . Kết quả khảo sát được trình bày ở Bảng 1 và Hình 5 .

Phân tích kết quả thu được ở Hình 5 và so sánh hệ số tương quan của các mô hình (Bảng 1) cho thấy quá trình hấp phụ $\mathrm{MB}$ được mô tả tốt hơn với mô hình động học biểu kiến bậc một và mô hình đẳng nhiệt Freundlich, trong khi đó sự hấp phụ Ni(II) phù hợp với mô hình động học biểu kiển bậc một và mô hình Langmuir.

Bảng 1. Các thông số động học và đẳng nhiệt hấp phụ của $\mathrm{Fe}_{3} \mathrm{O}_{4} @ \mathrm{CRC}$ đối với $\mathrm{MB}$ và $\mathrm{Ni}(\mathrm{II})$

\begin{tabular}{|l|c|c|l|c|c|}
\hline Mô hình động học & $\mathrm{MB}$ & $\mathrm{Ni}(\mathrm{II})$ & Mô hình đắng nhiệt & $\mathrm{MB}$ & $\mathrm{Ni}(\mathrm{II})$ \\
\hline Bậc 1 & & & Langmuir & & \\
\hline $\mathrm{q}_{\mathrm{e}, \mathrm{tn}}(\mathrm{mg} / \mathrm{g})$ & 145,09 & 81,94 & $\mathrm{q}_{\mathrm{m}}(\mathrm{mg} / \mathrm{g})$ & 187,26 & 106,75 \\
\hline $\mathrm{q}_{\mathrm{e}, \mathrm{t}}(\mathrm{mg} / \mathrm{g})$ & 147,38 & 85,29 & $\mathrm{~K}_{\mathrm{L}}(\mathrm{L} / \mathrm{mg})$ & 0,124 & 0,354 \\
\hline $\mathrm{k}_{1}(1 / \mathrm{phút})$ & 0,105 & 0,127 & $\mathrm{R}^{2}$ & 0,957 & 0,982 \\
\hline $\mathrm{R}^{2}$ & 0,999 & 0,998 & & & \\
\hline Bậc 2 & & & Freundlich & & \\
\hline $\mathrm{q}_{\mathrm{e}, \mathrm{tn}}(\mathrm{mg} / \mathrm{g})$ & 168,11 & 96,41 & $\mathrm{~K}_{\mathrm{F}}\left[(\mathrm{mg} / \mathrm{g}) .(\mathrm{L} / \mathrm{mg})^{1 / \mathrm{n}}\right]$ & 57,89 & 51,81 \\
\hline $\mathrm{k}_{2}(\mathrm{~g} / \mathrm{mg} / \mathrm{phút})$ & $8,01 \times 10^{-4}$ & $1,65 \times 10^{-3}$ & $1 / \mathrm{n}$ & 0,224 & 0,149 \\
\hline $\mathrm{R}^{2}$ & 0,983 & 0,978 & $\mathrm{R}^{2}$ & 0,991 & 0,953 \\
\hline
\end{tabular}



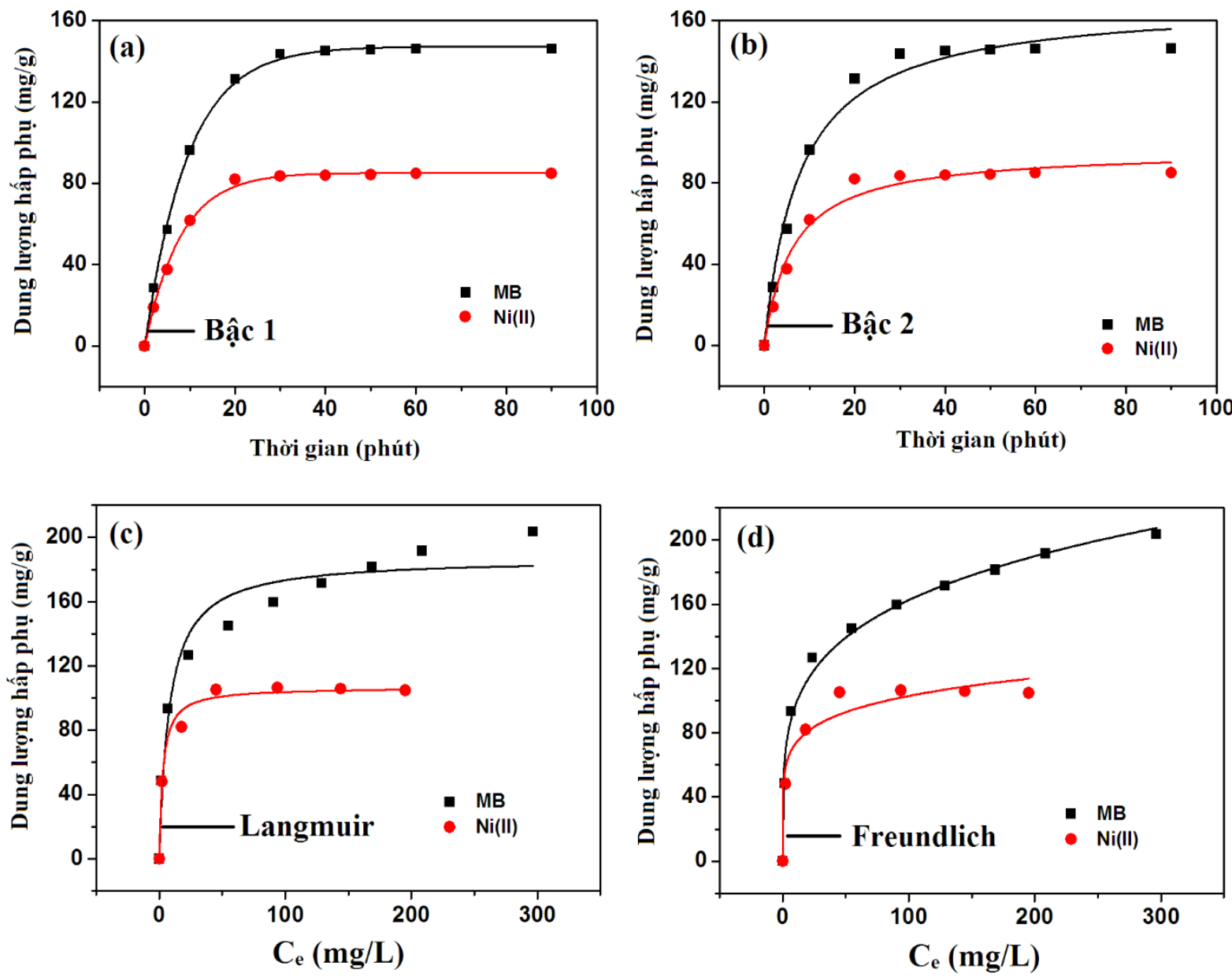

Hình 5. Mô hình động học $(\mathrm{a}, \mathrm{b})$ và đẳng nhiệt hấp phụ $(\mathrm{c}, \mathrm{d})$ của $\mathrm{MB}$ và $\mathrm{Ni}(\mathrm{II})$ trên vật liệu $\mathrm{Fe}_{3} \mathrm{O}_{4} @ \mathrm{CRC}$.

Bảng 2. Bảng so sánh dung lượng hấp phụ của một số vật liệu đối với MB và Ni(II)

\begin{tabular}{|c|c|c|c|}
\hline Chất ô nhiễm & Vật liệu hấp phụ & $\mathrm{q}_{\mathrm{m}}(\mathrm{mg} / \mathrm{g})$ & Tài liệu tham khảo \\
\hline \multirow{5}{*}{ MB } & Ống nano cacbon từ tính & 15,90 & [30] \\
\hline & Nano polymer xốp gắn nhóm carboxyl & 57,74 & [31] \\
\hline & ZnS:Cu/than hoạt tính & 123,46 & [32] \\
\hline & $\mathrm{Fe}_{3} \mathrm{O}_{4} @ \mathrm{CRC}$ & 187,26 & Nghiên cứu này \\
\hline & Than hoạt tính từ tính từ mùn cưa & 228,22 & [33] \\
\hline \multirow{5}{*}{$\mathrm{Ni}(\mathrm{II})$} & $\mathrm{Fe}_{3} \mathrm{O}_{4} / \mathrm{GO} /$ chitosan & 12,24 & [34] \\
\hline & Than hoạt tính từ xơ dừa & 62,5 & [35] \\
\hline & $\mathrm{Fe}_{3} \mathrm{O}_{4} / \mathrm{GO} /$ chitosan (dạng hạt) & 80,48 & [17] \\
\hline & $\mathrm{Fe}_{3} \mathrm{O}_{4} @ \mathrm{CRC}$ & 106,75 & Nghiên cứu này \\
\hline & $\mathrm{Fe}_{3} \mathrm{O}_{4} /$ than hoạt tính/chitosan & 108,70 & [5] \\
\hline
\end{tabular}


Hệ số tốc độ của $\mathrm{Ni}(\mathrm{II})\left(k_{1}=0,127\right)$ cao hơn so với $\mathrm{MB}\left(k_{1}=0,105\right)$, chứng tỏ quá trình hấp phụ của $\mathrm{Ni}(\mathrm{II})$ bởi $\mathrm{Fe}_{3} \mathrm{O}_{4} @ \mathrm{CRC}$ diễn ra nhanh hơn MB. Bên cạnh đó, các giá trị của tham số $1 / n$ trong mô hình Freundlich nằm trong khoảng từ $0-1$, cho thấy sự hấp phụ của $\mathrm{MB}$ và $\mathrm{Ni}(\mathrm{II})$ trên các bề mặt vật liệu diễn ra thuận lợi. Dung lượng hấp phụ cực đại tính theo mô hình Langmuir đối với $\mathrm{MB}$ và $\mathrm{Ni}(\mathrm{II})$ tương ứng là $187,26 \mathrm{mg} / \mathrm{g}$ và $106,75 \mathrm{mg} / \mathrm{g}$. So với khả năng hấp phụ của một số vật liệu khác (Bảng 2), $\mathrm{Fe}_{3} \mathrm{O}_{4} @$ @ CRC có khả năng hấp phụ tương đối cao đối với cả $\mathrm{MB}$ và $\mathrm{Ni}(\mathrm{II})$.

\subsection{Các thông số nhiệt học}

Các thông số nhiệt động lực học hấp phụ như năng lượng tự do Gibbs $(\Delta \mathrm{G})$, entanpi $(\Delta \mathrm{H})$ và entropi $(\Delta \mathrm{S})$ sẽ được tính toán theo các phương trình sau:

$$
\begin{gathered}
\Delta G=-R T \ln K_{c} \\
L n K_{c}=\frac{\Delta S}{R}-\frac{\Delta H}{R T} \\
K_{c}=\frac{C_{a d}}{C_{e}}
\end{gathered}
$$

Trong đó: $R$ là hằng số khí; $K_{c}$ là hằng số cân bằng hấp phụ; $C_{a d}(\mathrm{mg} / \mathrm{L})$ và $C_{e}(\mathrm{mg} / \mathrm{L})$ lần lượt là nồng độ cân bằng của chất được hấp phụ trên bề mặt vật liệu và trong dung dịch. Giá trị $\Delta \mathrm{H}$ và $\Delta \mathrm{S}$ sẽ được tính toán dựa trên phương trình tuyến tính thể hiện phụ thuộc giữa $L n K_{c}$ và $1 / T$ (Hình 6). Các thông số nhiệt học được đưa vào Bảng 3.

Từ Bảng 3 có thể thấy, $\Delta \mathrm{G}$ tại tất cả các nhiệt độ khảo sát đều mang giá trị âm, điều này chứng tỏ quá trình hấp phụ của $\mathrm{Ni}(\mathrm{II})$ và $\mathrm{MB}$ trên $\mathrm{Fe}_{3} \mathrm{O}_{4} @ \mathrm{CRC}$ là quá trình tự phát, tức là tự diễn ra mà không cần xúc tác. Ngoài ra, giá trị $\Delta \mathrm{G}$ tăng khi nhiệt độ tăng khẳng định quá trình hấp phụ của $\mathrm{MB}$ và $\mathrm{Ni}$ (II) trên bề mặt $\mathrm{Fe}_{3} \mathrm{O}_{4} @ \mathrm{CRC}$ thuận lợi ở nhiệt độ cao và chủ yếu là hấp phụ hóa học.

Giá trị dương của $\Delta \mathrm{H}$ và $\Delta \mathrm{S}$ chứng tỏ quá trình hấp phụ của $\mathrm{Fe}_{3} \mathrm{O}_{4} @ \mathrm{CRC}$ đối với $\mathrm{Ni}$ (II) và MB là quá trình thu nhiệt và mức độ tự do của các phân tử trong dung dịch tăng lên tại bề mặt phân cách rắn - lỏng [5].

\subsection{Khả năng tái sử dụng của vật liệu}

Ưu điểm nổi bật của vật liệu từ tính là có thể dễ dàng thu hồi và tái sử dụng nhiều lần. Việc sử dụng lâu dài một chất hấp phụ luôn được quan tâm bởi vì nó là một yếu tố quan trọng giúp giảm chi phí khi ứng dụng thực tế.

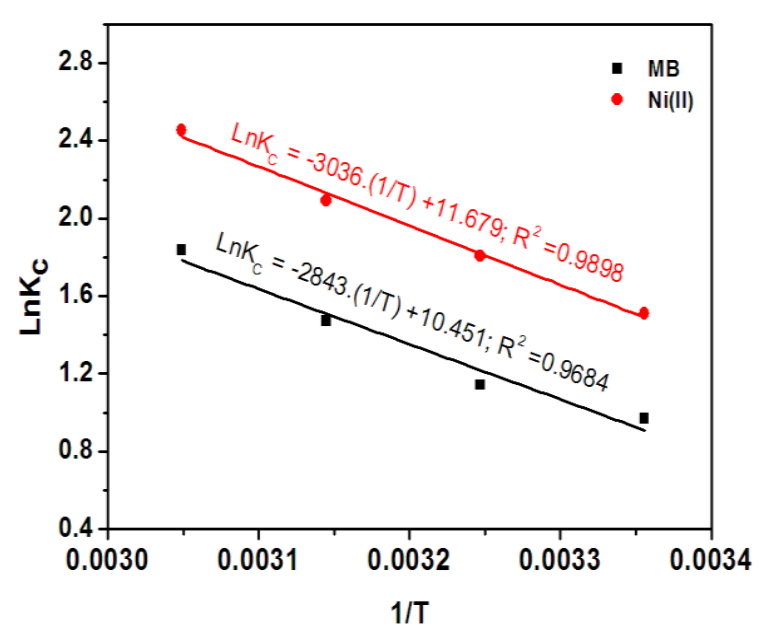

Hình 6. Sự phụ thuộc của $\ln K_{c}$ vào nhiệt độ $1 / T$.

Bảng 3. Các thông số nhiệt học của quá trình hấp phụ $\mathrm{MB}$ và $\mathrm{Ni}(\mathrm{II})$ trên $\mathrm{Fe}_{3} \mathrm{O}_{4} @ \mathrm{CRC}$

\begin{tabular}{|l|c|c|c|c|c|c|}
\hline & \multirow{2}{*}{$\Delta \mathrm{H}(\mathrm{kJ} / \mathrm{mol})$} & \multirow{4}{*}{$\begin{array}{c}\triangle \mathrm{S} \\
(\mathrm{J} / \mathrm{mol} / \mathrm{K})\end{array}$} & \multicolumn{4}{|c|}{$\triangle \mathrm{G}(\mathrm{kJ} / \mathrm{mol})$} \\
\cline { 4 - 7 } & & 86,88 & $-2,41$ & $-2,93$ & $-3,89$ & $-5,01$ \\
\hline $\mathrm{MB}$ & 23,64 & 97,10 & $-3,75$ & $-4,63$ & $-5,53$ & $-6,69$ \\
\hline $\mathrm{Ni}(\mathrm{II})$ & 25,24 & &
\end{tabular}




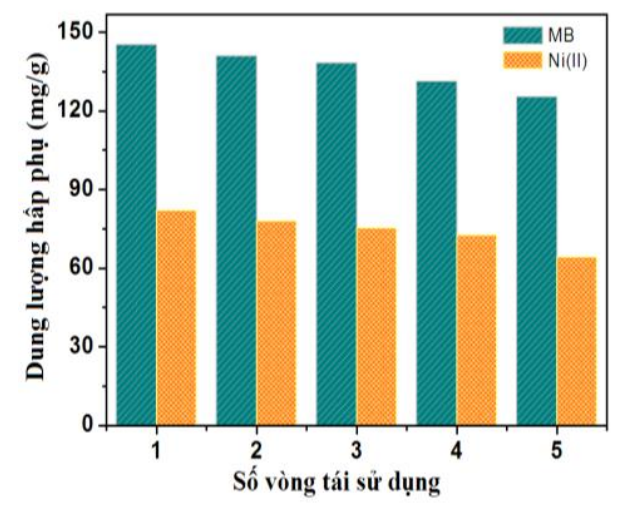

Hình 7. Dung lượng hấp phụ của MB và Ni(II) trên $\mathrm{Fe}_{3} \mathrm{O}_{4} @$ CRC qua các lần tái sử dụng.

Trong nghiên cứu này, khả năng tái sử dụng của vật liệu $\mathrm{Fe}_{3} \mathrm{O}_{4} @$ @RC được khảo sát qua 5 vòng hấp phụ-giải hấp phụ liên tiếp. Sau mỗi lần hấp phụ, vật liệu hấp phụ chứa chất bị hấp phụ được ngâm trong dung dịch $\mathrm{HCl} 0,1 \mathrm{M}$ trong $24 \mathrm{~h}$ để giải hấp, sau đó sấy khô hoàn toàn trước khi sử dụng nó để hấp phụ trong các vòng tiếp theo. Các điều kiện thí nghiệm được chọn ở các giá trị tối ưu. Kết quả được thể hiện ở Hình 7. Từ Hình 7 cho thấy khi tăng số lần tái sử dụng dung lượng hấp phụ của $\mathrm{Fe}_{3} \mathrm{O}_{4} @ \mathrm{CRC}$ giảm dần. Có thể thấy rằng sau năm chu kỳ, khả năng hấp phụ của $\mathrm{Fe}_{3} \mathrm{O}_{4} @ \mathrm{CRC}$ đối với $\mathrm{MB}$ và $\mathrm{Ni}(\mathrm{II})$ giảm từ $145,09 \mathrm{mg} / \mathrm{g}$ và $81,94 \mathrm{mg} / \mathrm{g}$ xuống còn 130,28 $\mathrm{mg} / \mathrm{g}$ và $68,32 \mathrm{mg} / \mathrm{g}$, tương ứng giảm $10,21 \%$ và $16,62 \%$ so với lần hấp phụ đầu tiên. Sự giảm này có thể là do hai nguyên nhân chính đó là: sự mất dần các tâm hấp phụ qua nhiều lần tái sử dụng và sự giải hấp chưa diễn ra hoàn toàn do các ion $\mathrm{Ni}(\mathrm{II})$ và phân tử $\mathrm{MB}$ còn bị giữ chặt trong $\mathrm{Fe}_{3} \mathrm{O}_{4} @ \mathrm{CRC}$. Bên cạnh đó, khối lượng của mẫu $\mathrm{Fe}_{3} \mathrm{O}_{4} @ \mathrm{CRC}$ sau 5 lần sử dụng giảm không đáng kể chỉ $1,62 \%$ chứng tỏ vật liệu khá bền và hiệu suất thu hồi khá cao.

\section{Kết luận}

Vật liệu cacbon từ tính giàu cacboxylat đã được tổng hợp thành công bằng phương pháp nhiệt phân ở nhiệt độ thấp và ứng dụng để xử lý $\mathrm{Ni}(\mathrm{II})$ và phẩm màu nhuộm $\mathrm{MB}$. Kết quả phân tích $\mathrm{SEM}$ và $\mathrm{TEM}$ cho thấy $\mathrm{Fe}_{3} \mathrm{O}_{4} @ \mathrm{CRC}$ tổ hợp từ các hạt nano $\mathrm{Fe}_{3} \mathrm{O}_{4}$ kích thước khoảng 10-20 nm được phân bố đều trên CRC dạng mảnh có chiều dài $2-10 \mu \mathrm{m}$ với độ dày $0,5-2 \mu \mathrm{m}$. Nhờ sở hữu diện tích bề mặt lớn $\left(308,7 \mathrm{~m}^{2} / \mathrm{g}\right)$ và có từ tính $(30,02 \mathrm{emu} / \mathrm{g}), \mathrm{Fe}_{3} \mathrm{O}_{4} @ \mathrm{CRC}$ thể hiện khả năng hấp phụ cao đối với cả $\mathrm{Ni}(\mathrm{II})$ và $\mathrm{MB}$, và dễ dàng thu hồi sau hấp phụ bằng cách sử dụng kỹ thuật tách từ tính. Quá trình hấp phụ của $\mathrm{MB}$ và $\mathrm{Ni}$ (II) trên $\mathrm{Fe}_{3} \mathrm{O}_{4} @ \mathrm{CRC}$ là quá trình tự phát, thu nhiệt và được mô tả tốt với mô hình động học bậc một, mô hình đẳng nhiệt Freundlich (đối với $\mathrm{MB}$ ) và Langmuir (đối với $\mathrm{Ni}(\mathrm{II})$. Dung lượng hấp phụ cực đại của $\mathrm{Fe}_{3} \mathrm{O}_{4} @ \mathrm{CRC}$ đối với $\mathrm{MB}$ và $\mathrm{Ni}(\mathrm{II})$ được xác định có giá trị lần lượt là 187,26 $\mathrm{mg} / \mathrm{g}$ và $106,75 \mathrm{mg} / \mathrm{g}$. Bên cạnh đó, kết quả khảo sát khả năng tái sử dụng cho thấy $\mathrm{Fe}_{3} \mathrm{O}_{4} @ \mathrm{CRC}$ duy trì tốt khả năng hấp phụ qua nhiều lần sử dụng, sau 5 lần tái sử dụng chỉ giảm khoảng $10,21 \%$ (đối với $\mathrm{MB}$ ) và $16,62 \%$ (đối với $\mathrm{Ni}(\mathrm{II})$ ) so với lần hấp phụ đầu tiên. Như vậy, $\mathrm{Fe}_{3} \mathrm{O}_{4} @ \mathrm{CRC}$ có thể trở thành chất hấp thụ tiềm năng để loại bỏ ion kim loại nặng và phẩm màu nhuộm độc hại ra khỏi nước thải công nghiệp do quy trình tổng hợp đơn giản, hiệu suất xử lý tốt và khả năng thu hồi tái sử dụng cao.

\section{Lò̀i cảm ơn}

Nghiên cứu này được tài trợ bởi Quỹ Phát triển khoa học và công nghệ Quốc gia (NAFOSTED) trong đề tài mã số 104.052019.03.

\section{Tài liệu tham khảo}

[1] Z. Li, L. Li, D. Hu, C. Gao, J. Xiong, H. Jiang, W. Li, Efficient Removal of Heavy Metal Ions and Organic Dyes with Cucurbit [8] UrilFunctionalized Chitosan, Journal of Colloid and Interface Science, Vol. 539, 2019, pp. 400-413. https://doi.org/10.1016/j.jcis.2018.12.078.

[2] H. Cangul, L. Broday, K. Salnikow, J. Sutherland, W. Peng, Q. Zhang, V. Poltaratsky, H. Yee, M.A. Zoroddu, M. Costa, Molecular Mechanisms of Nickel Carcinogenesis, Toxicology Letters, Vol. 127, No. 1-3, 2002, pp. 69-75. https://doi.org/10.1016/S0378-4274(01)00485-4. 
[3] V. D. Doan, T. L. Do, T. M. T. Ho, V. T. Le, H. T. Nguyen, Utilization of Waste Plastic Pet Bottles to Prepare Copper-1,4Benzenedicarboxylate Metal-Organic Framework for Methylene Blue Removal, Separation Science and Technology, Vol. 55, No. 3, 2020, pp. 444-455, https://doi.org/10.1080/01496395.2019.1577266.

[4] M. Visa, C. Bogatu, A. Duta, Simultaneous Adsorption of Dyes and Heavy Metals from Multicomponent Solutions using Fly Ash, Applied Surface Science, Vol. 256, No. 17, 2010, pp. 5486-5491, https://doi.org/10.1016/j.apsusc.2009.12.145.

[5] V. T. Le, M. U. Dao, H. S. Le, D. L. Tran, V. D. Doan, H. T. Nguyen, Adsorption of Ni(II) Ions By Magnetic Activated Carbon/Chitosan Beads Prepared from Spent Coffee Grounds, Shrimp Shells and Green Tea Extract, Environmental Technology, Vol. 41, No. 21, 2020 , pp. 2817-2832, https://doi.org/10.1080/09593330.2019.1584250.

[6] M. Karnib, A. Kabbani, H. Holail, Z. Olama, Heavy Metals Removal using Activated Carbon, Silica and Silica Activated Carbon Composite, Energy Procedia, Vol. 50, 2014, pp. 113-120, https://doi.org/10.1016/j.egypro.2014.06.014.

[7] J. Shu, S. Cheng, H. Xia, L. Zhang, J. Peng, C. Li, S. Zhang, Copper Loaded on Activated Carbon as an Efficient Adsorbent for Removal of Methylene Blue, RSC Advances, Vol. 7, No. 24, 2017, pp. 1439-14405, https://doi.org/10.1039/C7RA00287D.

[8] Z. Ioannou, C. Karasavvidis, A. Dimirkou, V. Antoniadis, Adsorption of Methylene Blue and Methyl Red Dyes from Aqueous Solutions onto Modified Zeolites, Water Science and Technology, Vol. 67, No. 5, 2013, pp. 1129-1136, https://doi.org/10.2166/wst.2013.672.

[9] E. Zanin, J. Scapinello, M. de Oliveira, C. L. Rambo, F. Franscescon, L. Freitas, J. M. M. de Mello, M. A. Fiori, J. V. Oliveira, J. Dal Magro, Adsorption of Heavy Metals from Wastewater Graphic Industry using Clinoptilolite Zeolite as Adsorbent, Process Safety and Environmental Protection, Vol. 105, 2017, pp. 194-200, https://doi.org/10.1016/j.psep.2016.11.008.

[10] F. Y. Wang, H. Wang, J. W. Ma, Adsorption of Cadmium(II) Ions from Aqueous Solution by a New Low-Cost Adsorbent-Bamboo Charcoal, Journal of Hazardous Materials, Vol. 177, No. 1-3, 2010, pp. 300-306, https://doi.org/10.1016/j.jhazmat.2009.12.032.

[11] W. S. W. Ngah, L. C. Teong, M. A. K. M. Hanafiah, Adsorption of Dyes and Heavy Metal Ions by Chitosan Composites: A Review, Carbohydrate
Polymers, Vol. 83, No. 4, 2011, pp. 1446-1456, https://doi.org/10.1016/j.carbpol.2010.11.004.

[12] Y. Feng, J. L. Gong, G. M. Zeng, Q. Y. Niu, H. Y. Zhang, C. G. Niu, J. H. Deng, M. Yan, Adsorption of $\mathrm{Cd}$ (II) and $\mathrm{Zn}$ (II) from Aqueous Solutions using Magnetic Hydroxyapatite Nanoparticles as Adsorbents, Chemical Engineering Journal, Vol. 162, No. 2, 2010, pp. 487-494, https://doi.org/10.1016/j.cej.2010.05.049.

[13] F. Perreault, A. Fonseca de Faria, M. Elimelech, Environmental Applications of Graphene-Based Nanomaterials, Chemical Society Reviews, Vol. 44, No. 16, 2015, pp. 5861-5896, https://doi.org/10.1039/C5CS00021A.

[14] E. Santoso, R. Ediati, Y. Kusumawati, H. Bahruji, D.O. Sulistiono, D. Prasetyoko, Review on Recent Advances of Carbon Based Adsorbent for Methylene Blue Removal from Waste Water, Materials Today Chemistry, Vol. 16, 2020, pp. 100233 , https://doi.org/10.1016/j.mtchem.2019.100233.

[15] L. Qu, D. Huang, H. Shi, M. Gu, J. Li, F. Dong, Z. Luo, $\mathrm{TiO}_{2} /$ Carboxylate-rich Porous Carbon: A Highly Efficient Visible-Light-Driven Photocatalyst Based on the Ligand-to-Metal Charge Transfer (LMCT) Process, Journal of Physics and Chemistry of Solids, Vol. 85, 2015, pp. 173-179, https://doi.org/10.1016/j.jpcs.2015.05.016.

[16] Q. Wu, W. Li, S. Liu, Carboxyl-rich Carbon Microspheres Prepared from Pentosan with High Adsorption Capacity for Heavy Metal Ions, Materials Research Bulletin, Vol. 60, 2014, pp. 516-523, https://doi.org/10.1016/j.materresbull.2014.09.01.

[17] T. T. N. Le, V. T. Le, M. U. Dao, Q. V. Nguyen, T. T. Vu, M. H. Nguyen, D. L. Tran, H. S. Le, Preparation of Magnetic Graphene Oxide/Chitosan Composite Beads for Effective Removal of Heavy Metals and Dyes from Aqueous Solutions, Chemical Engineering Communications, Vol. 206, No. 10, 2019, pp. 1337-1352, https://doi.org/10.1080/00986445.2018.1558215.

[18] F. Cheng, Characterization of Aqueous Dispersions of $\mathrm{Fe}_{3} \mathrm{O}_{4}$ Nanoparticles and their Biomedical Applications, Biomaterials, Vol. 26, No. 7, 2005, pp. 729-738, https://doi.org/10.1016/j.biomaterials.2004.03.01.

[19] S. Mahdavi, M. Jalali, A. Afkhami, Removal of Heavy Metals from Aqueous Solutions using $\mathrm{Fe}_{3} \mathrm{O}_{4}, \mathrm{ZnO}$, and $\mathrm{CuO}$ Nanoparticles, in: Nanotechnology for Sustainable Development First Ed., 2014, https://doi.org/10.1007/978-3-31905041-614. 
[20] G. R. Chaudhary, P. Saharan, A. Kumar, S. K. Mehta, S. Mor, A. Umar, Adsorption Studies of Cationic, Anionic and Azo-Dyes via Monodispersed $\mathrm{Fe}_{3} \mathrm{O}_{4}$ Nanoparticles, Journal of Nanoscience and Nanotechnology, Vol. 13, No. 5, 2013, pp 3240-3245, https://doi.org/10.1166/jnn.2013.7152.

[21] L. Qu, J. Jia, H. Shi, Z. Luo, One-step Synthesis of $\mathrm{Fe}_{3} \mathrm{O}_{4} /$ Carboxylate-rich Carbon Composite and its Application for $\mathrm{Cu}$ (II) Removal, New Journal of Chemistry, Vol. 40, No. 3, 2016, pp. 2895-2903, https://doi.org/10.1039/c5nj02545a.

[22] L. Qu, Z. Luo, C. Tang, One Step Synthesis of $\mathrm{Bi} @ \mathrm{Bi}_{2} \mathrm{O}_{3} @$ Carboxylate-rich Carbon Spheres with Enhanced Photocatalytic Performance, Materials Research Bulletin, Vol. 48, No. 11, 2013 , pp. 4601-4605,

https://doi.org/10.1016/j.materresbull.2013.07.04.

[23] V. T. Le, T. K. N. Tran, D. L. Tran, H. S. Le, V. D. Doan, Q. D. Bui, H. T. Nguyen, One-pot Synthesis of a Novel Magnetic Activated Carbon/Clay Composite for Removal of Heavy Metals from Aqueous Solution, Journal of Dispersion Science and Technology, Vol. 40, No. 12, 2019, pp. 1761-1776, https://doi.org/10.1080/01932691.2018.1541414.

[24] X. Zhang, A. Lu, D. Li, L. Shi, Z. Luo, C. Peng, Simultaneous Removal of Methylene Blue and $\mathrm{Pb}^{2+}$ from Aqueous Solution by Adsorption on Facile Modified Lignosulfonate, Environmental Technology (United Kingdom), Vol. 41, No. 13, 2018, pp 1677-1690, https://doi.org/10.1080/09593330.2018.1544666.

[25] M. J. Livani, M. Ghorbani, Fabrication of $\mathrm{NiFe}_{2} \mathrm{O}_{4}$ Magnetic Nanoparticles Loaded on Activated Carbon as Novel Nanoadsorbent for Direct Red 31 and Direct Blue 78 Adsorption, Environmental Technology (United Kingdom). Vol. 39, No. 23, 2018, pp. 2977-2993, https://doi.org/10.1080/09593330.2017.1370024.

[26] N. Baig, Ihsanullah, M. Sajid, T. A. Saleh, Graphene-based Adsorbents for the Removal of Toxic Organic Pollutants: A Review, Journal of Environmental Management, Vol. 244, 2019, pp. 370-382, https://doi.org/10.1016/j.jenvman.2019.05.047.

[27] A. Kuroki, M. Hiroto, Y. Urushihara, T. Horikawa, K. I. Sotowa, J. R. Alcántara Avila, Adsorption Mechanism of Metal Ions on Activated Carbon, Adsorption, Vol. 25, No. 9, 2019, pp. 1251-1258, https://doi.org/10.1007/s10450-019-00069-7.
[28] M. Jiang, X. Jin, X.-Q. Lu, Z. Chen, Adsorption of $\mathrm{Pb}(\mathrm{II}), \mathrm{Cd}(\mathrm{II}), \mathrm{Ni}(\mathrm{II})$ and $\mathrm{Cu}(\mathrm{II})$ onto Natural Kaolinite Clay, Desalination, Vol. 252, No. 1-3, 2010, pp. 33-39. https://doi.org/10.1016/j.desal.2009.11.005.

[29] N. S. Yousef, R. Farouq, R. Hazzaa, Adsorption Kinetics And Isotherms for the Removal of Nickel Ions from Aqueous Solutions by an Ion-Exchange Resin: Application of Two and Three Parameter Isotherm Models, Desalination and Water Treatment, Vol. 57, No. 46, 2016, pp. 21925-21938, https://doi.org/10.1080/19443994.2015.1132474.

[30] J. L. Gong, B. Wang, G. M. Zeng, C. P. Yang, C. G. Niu, Q. Y. Niu, W. J. Zhou, Y. Liang, Removal of Cationic Dyes from Aqueous Solution using Magnetic Multi-Wall Carbon Nanotube Nanocomposite as Adsorbent, Journal of Hazardous Materials, Vol. 164, No. 2-3, 2009, pp. $1517-1522$, https://doi.org/10.1016/j.jhazmat.2008.09.072.

[31] H. Su, W. Li, Y. Han, N. Liu, Magnetic Carboxyl Unctional Nanoporous Polymer: Synthesis, Characterization and its application for Methylene Blue Adsorption, Scientific Reports, Vol. 8, No. 6506, 2018, pp. 1-8, https://doi.org/10.1038/s41598-018-24873-3.

[32] A. Asfaram, M. Ghaedi, S. Hajati, A. Goudarzi, A. A. Bazrafshan, Simultaneous UltrasoundAssisted Ternary Adsorption of Dyes onto CopperDoped Zinc Sulfide Nanoparticles Loaded on Activated Carbon: Optimization by Response Surface Methodology, Spectrochimica Acta Part A: Molecular and Biomolecular Spectroscopy, Vol. 145, No. 15, 2015, pp. 203-212, https://doi.org/10.1016/j.saa.2015.03.006.

[33] C. Chen, S. Mi, D. Lao, P. Shi, Z. Tong, Z. Li, H. Hu, Single-step Synthesis of Eucalyptus Sawdust Magnetic Activated Carbon and its Adsorption Behavior for Methylene Blue, RSC Advances, Vol. 9, No. 39, 2019, pp. 22248-22262, https://doi.org/10.1039/C9RA03490K.

[34] L. T. Tran, H. V. Tran, T. D. Le, G. L. Bach, L. D. Tran, Studying Ni(II) Adsorption of Magnetite/Graphene Oxide/Chitosan Nanocomposite, Advances in Polymer Technology, Vol. 2019. 2019, pp. 1-9, https://doi.org/10.1155/2019/8124351.

[35] K. Kadirvelu, Adsorption of Nickel(II) from Aqueous Solution onto Activated Carbon Prepared from Coirpith, Separation and Purification Technology, Vol. 24, No. 3, 2001, pp. 497-505, https://doi.org/10.1016/S1383-5866(01)00149-6. 